\title{
Comparison of structural diversity of tree-crop associations in Periph- eral and Buffer zones of Gachabari Sal forest area, Bangladesh
}

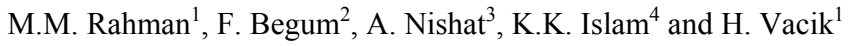 \\ ${ }^{1}$ Institute of Silviculture, Department of Forest and Soil Sciences, University of Natural Resources and Applied Life Sciences, Vienna, Austria \\ ${ }^{2}$ Department of Agronomy, Bangladesh Agricultural University, Mymensingh-2202. Bangladesh \\ ${ }^{3}$ The World Conservation Union (IUCN) Bangladesh Country Office. \\ ${ }^{4}$ Department of Agroforestry, Bangladesh Agricultural University, Mymensingh-2202. Bangladesh
}

Erratum to: Journal of Forestry Research

DOI: $10.1007 / \mathrm{s} 11676-007-0004-1$

The original version of this article unfortunately contained three mistakes.

(1) The spelling of the [A. Nishad'] name was incorrect. The corrected spelling is given below.

A. Nishat

(2) The sequence of the author names was incorrect. The corrected sequence of the author names is given below.

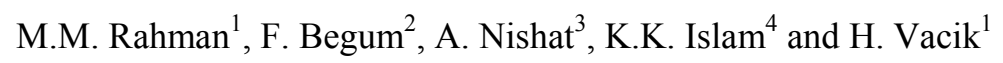

(3) One of the affiliations was incorrect. The correct information is given below.

${ }^{3}$ The World Conservation Union (IUCN) Bangladesh Country Office. 